\title{
THE ATTITUDES OF ANIMALS IN MOTION.
}

\section{By Eadweard Muybridge, of San Francisco.}

[A lecture delivered before the Franklin Institute, February 13th, 1883.]

The problem of animal mechanism has engaged the attention of mankind during the entire period of the world's history.

Job describes the action of the horse; Homer, that of the ox; it engaged the profound attention of Aristotle, and Borelli devoted a lifetime to its attempted solution. In every age and in every country, philosophers have found it a subject of exhaustless research. Marey, the eminent French savant of our own day, dissatisfied with the investigations of his predecessors, and with the object of obtaining more accurate information than their works afforded him, employed a system of flexible tubes, connected at one end with elastic air-chambers, which were attached to the shoes of a horse; and at the other end with some mechanism, held in the hand of the animal's rider. The alternate compression and expansion of the air in the chambers caused pencils to record upon a revolving cylinder the successive or simultaneous action of each foot, as it correspondingly rested upon or was raised from the ground. By this original and ingenious method, much interesting and valuable information was obtained, and new light thrown upon movements until then but imperfectly understood.

While the philosopher was exhausting his endeavors to expound the laws that control and the elements that effect the movements associated with animal life, the artist, with a few exceptions, seems to have been content with the observations of his earliest predecessors in design, and to have accepted as authentic without further inquiry, the pictorial and sculptural representations of moving animals bequeathed from the remote ages of tradition.

When the body of an animal is being carried forward with uniform motion, the limbs in their relations to it have alternately a progressive and a retrogressive action, their various portions accelerating in comparative speed and repose as they extend downwards to the feet, which are subjected to successive changes from a condition of absolute rest, to a varying increased velocity in comparison with that of the body.

The action of no single limb can be availed of for artistic purposes without a knowledge of the synchronous action of the other limbs; and to the extreme difficulty, almost impossibility, of the mind being 
capable of appreciating the simultaneous motion of the four limbs of an animal, even in the slower movements, may be attributed the innumerable errors into which investigators by observation have been betrayed. When these synchronous movements and the successive attitudes they occasion are understood, we at once see the simplicity of animal locomotion, in all its various types and alternations. 'The walk of a quadruped being its slowest progressive movement would seem to be a very simple action, easy of observation and presentirg but little difficulty for analysis, yet it has occasioned interminable controversies among the closest and most experienced observers.

When, during a gallop, the fore and hind legs are severally and consecutively thrust forwards and backwards to their fullest extent, their comparative inaction may create in the mind of the careless observer an impression of indistinct outlines; these successive appearances were probably combined by the earliest sculptors and painters, and with grotesque exaggeration adopted as the solitary position to illustrate great speed. Or, as is very likely, excessive projection of limb was intended to symbolize speed, just as excess in size was an indication of rank. This opinion is to some extent corroborated by the productions of the Grecian artists in their best period, when their heroes are represented of the same size as other men, and their horses in attitudes more nearly resembling those possible for them to assume. The remarkable conventional attitude of the Egyptians, however, has, with few modifications, been used by artists of nearly every age to represent the action of galloping, and prevails without recognized correction in all civilized countries at the present day.

The ambition and perhaps also the province of art in its most exalted sense, is to be a delineator of impressions, a creator of effects, rather than a recorder of facts. Whether in the illustrations of the attitudes of animals in motion the artist is justified in sacrificing truth, for an impression so vague as to be dispelled by the first studied observation, is a question perhaps as much a subject of controversy now as it was in the time of Lysippus, who ridiculed other senlptors for making men as they existed in nature; boasting that he himself made them as they ought to be.

A few eminent artists, notable among whom is Meissonier, have endeavored in depicting the slower movements of animals to invoke the aid of truth instead of imagination to direct their pencil, but with little encouragement from their critics; until recently, however, artists 
and critics alike have necessarily had to depend upon their observation alone to justify their conceptions or to support their theories.

Photography, at first regarded as a curiosity of science, was soon recognized as a most important factor in the search for truth, and its more popular use is now entirely subordinated by its value to the astronomer, the anatomist, the pathologist, and other investigators of the complex problems of nature. The artist, however, still hesitates to avail himself of the resources of what may be at least acknowledged as a handmaiden of art, if not admitted to its most exalted ranks.

Having devoted much attention in California to experiments in instantaneous photography, I, in 1872, at the suggestion of the editor of a San Francisco newspaper, obtained a few photographic impressions of a horse during a fast trot.

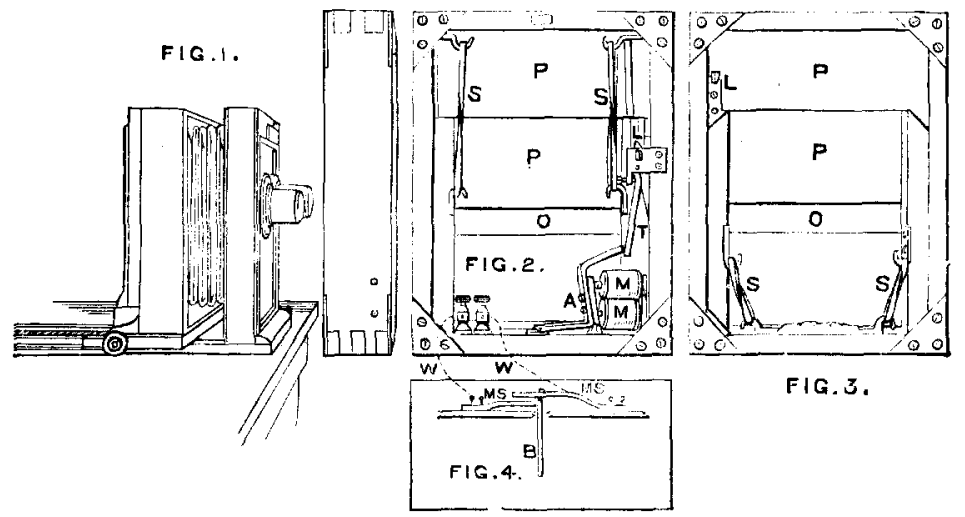

At this time much controversy prevailed among experienced horsemen as to whether all the feet of a horse while trotting were entirely clear of the ground at the same instant of time. A few experiments made in that year proved a fact which should have been self-evident.

Being much interested with the experiments of Professor Marey, in 1877 , I invented a method for the employment of a number of photographic cameras, arranged in a line parallel to a track over which the animal would be caused to move, with the object of obtaining, at regulated intervals of time or distance, several consecutive impressions of him during a single complete stride as he passed along in front of the cameras, and so of more completely investigating the successive attitudes of animals while in motion than could be accomplished by the system of M. Marey.

I explained the plan of my intended experiments to a wealthy res- 
ident of San Francisco-Mr. Stanford-who liberally agreed to place the resources of his stock-breeding farm at my disposal, and to reimburse the expenses of my investigations, upon condition of my supplying him, for his private use, with a few copies of the contemplated results. The apparatus used and its arrangement will be better understood by a reference to the accompanying drawings.

Fig. 1. A photographing lens, and camera containing a sensitised plate; and side view of electro-exposor placed in front of camera.

Fig. 2. Back view of electro-exposor. Two shutters P P, each comprising two panels, with an opening $O$ between them, are adjusted to move freely up and down in a frame; they are here arranged ready for an exposure, and are held in position by a latch $\mathrm{L}$ and trigger $\mathrm{T}$, all light being excluded from the lens. A slight extra tension of the thread B, Fig. 4, will cause a contact of the metal springs M S, and

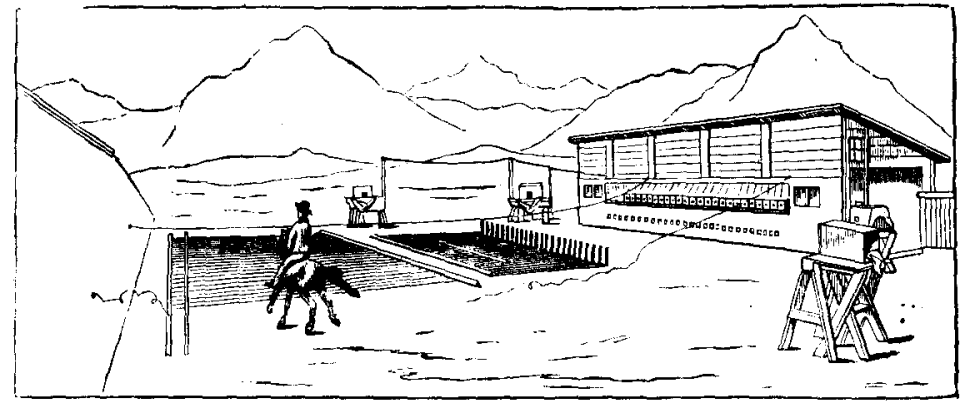

Fig. 5 .

complete a circuit of electricity through the wires $\mathrm{W} \mathrm{W}$ and the electromagnet $M$; the consequent attraction causes the armature $A$ to strike the trigger, the latch is released, the shutters are drawn respectively upwards and downwards by means of the rubber springs S S, and light is adinitted to the sensitised plate while the openings in the shutters are passing each other in front of the lens.

Fig. 3. Front view, of electro-exposor after exposure of the plate.

Fig. 5. General view of studio, operating track, and background. In the studio are arranged 24 photographing cameras; at a distance of 12 inches from the centre of each lens an electro-exposor is securely fixed in front of each camera. Threads 12 inches apart are stretched across the track (only two of which are introduced in the engraving), at a suitable height to strike the breast of the animal experimented with, one end of the thread being fastened to the background, the other to the spring, Fig. 4, which is drawn almost to the point of contact. 
The animal in its progress over the track will strike these threads in succeseion, and as each pair of strings is brought into contact, the current of electricity thereby created effects a photographic exposure, as described by Figs. 2 and 4 ; and each consecutive exposure records. the position of the animal at the instant the thread is struck and broken.

For obtaining successive exposures of horses driven in vehicles, one of the wheels is steered in a channel over wires slightly elevated from the ground; the depression of each wire completes an electric circuit, and effects the exposures in the same manner as the threads.

Fig. 6. Operating track, covered with corrugated India rubber, and marked with transverse lines 12 inches apart. Each line is numbered, for the purpose of more readily ascertaining the length of the animal's

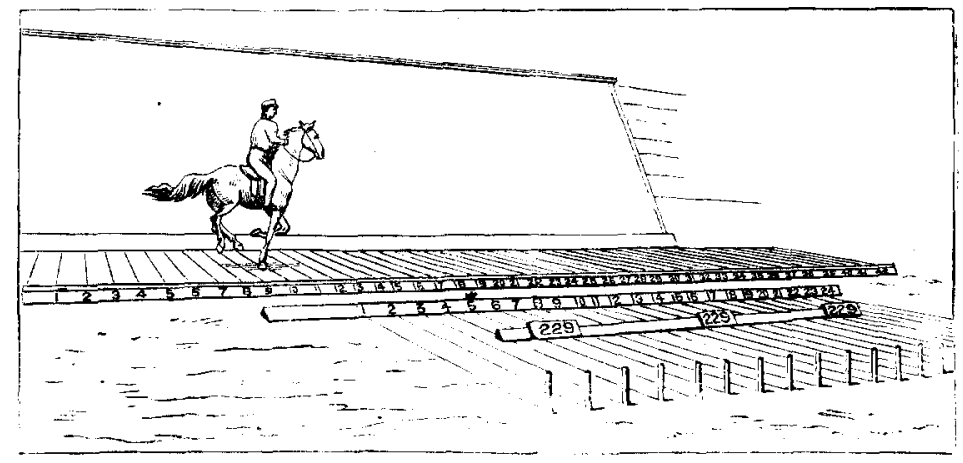

Fig. 6.

stride. On one side of the track, and opposite to the battery of cameras, a white background is erected at a suitable angle.

The camera in which any one negative in a series of exposures is made is designated on that negative by the parallel direction of the vertical stake with the horizontal line extending to the correspondingnumber immediately opposite. The discriminating number of each series is marked on each negative by the large numbers-229, for example-which are changed for each movement illustrated.

For recording the successive attitudes of animals not under control, an apparatus is used, comprising a cylinder, around which are spirally arranged a number of pins; upon the cylinder being set in motion through gearing connected with a spring or weight, these pins are consecutively brought into contact with a corresponding number of metal springs; a succession of electric currents is thereby created which act 
through their respective magnets attached to the electro-exposors at regulated intervals of time. The cylinder is put in motion either by bringing it into gearing with other parts of the apparatus already in motion; or by releasing a break with the hand, or by the action of some object at a distance by means of an electric current.

This apparatus is principally used for illustrating the flight of birds, the motions of small animals, and changes of position without continuous progressive motion, such as occur during wrestling or turning a somersault; when the cameras are directed towards the place where the movements are being executed.

The boxes outside the studio (Fig. 5) contain cameras and electroexposors for obtaining synchronous exposures of a moving object from different points of view.

The following analyses of some of the movements investigated by the aid of electro-photographic exposures, are rendered more perfectly intelligible by the reproductions of the actual motions projected on the screen through the zoöpraxiscope.

\section{THE WAIK.}

Selecting the horse for the purposes of illustration, we find that during. his slowest progressive movement-the walk - he has always two, and, for a varying period, three feet on the ground at once. With a fastwalking horse the time of support upon three feet is exceedingly brief; while during a very slow walk all four feet are occasionally on the ground at the same instant.

The successive order of what may be termed foot fallings are these. Commencing with the landing of the left hind foot, the next to strike the ground will be the left fore foot, followed in order by the right hind and right fore foot. So far as the camera has revealed, these successive foot fallings during the walk are invariable, and are probably common to all quadrupeds. But the time during which each foot, in its relation to the other feet, remains on the ground, varies greatly with different species of animals, and even with the same animal under different conditions. During an ordinary walk, at the instant preceding the striking of the left hind foot, the body is supported on the right laterals, and the left fore foot is in act of passing to the front of the right. fore foot. The two hind feet and the right fore foot immediately divide the weight. The right hind foot is now raised, and the left hind with its diagonal fore foot sustains the body; the left fore next touches the 
ground, and for an instant the animal is again on three feet; the right fore foot is immediately raised and again the support is derived from laterals-the left instead of as before the right. One-half of the stride is now completed, and a similar series of alternations, substituting the right feet for the left, completes the other half. These movements will perhaps be more readily understood by a reference to the longitudinal elevation, Fig. 7, No. 1, which illustrates some approximate relative positions of the feet of a rapid walking horse, with a stride of 5 feet 9 inches. The positions of the feet indicated in this, and also in the other strides illustrated in Fig. 7, are copied from photographs, and from them we learn that during an ordinary walk the consecutive supporting feet are-

1. The left hind and left fore-laterals.

2. Both hind, and left fore.

3. Right hind and left fore-diagonals.

4. Right hind and both fore.

5. Right hind and right fore-laterals.

6i. Both hind, and right fore.

7. Left hind and right fore-diagonals.

8. Left hind and both fore.

Commencing again with the first position; it is thus seen that when a horse during a walk is on two feet, and the other two feet are supended between the supporting legs, the suspended feet are laterals. On the other hand, when the suspended feet are severally in advance of and behind the supporting legs, they are diagonals.

These invariable rules seem to be neglected or entirely ignored by many of the most eminent animal painters of modern times.

THE TROT.

By some observers the perfect trot is described as an absolutely s'nchronous movement of the diagonal feet. This simultaneous action may be considered desirable, but it probably never occurs.

Sometimes the fore foot will be raised before the diagonal hind fort, sometimes afterwards; but in either instance, the foot raised first will strike the ground first; repeated experiments with many racing and other trotting horses confirmed this want of simultaneity. Selecting for an example of the trot a horse making a stride of 18 feet in length, we find that at the instant his right fore foot strikes the ground, the left hind foot is a few inches behind the point where it will presently 

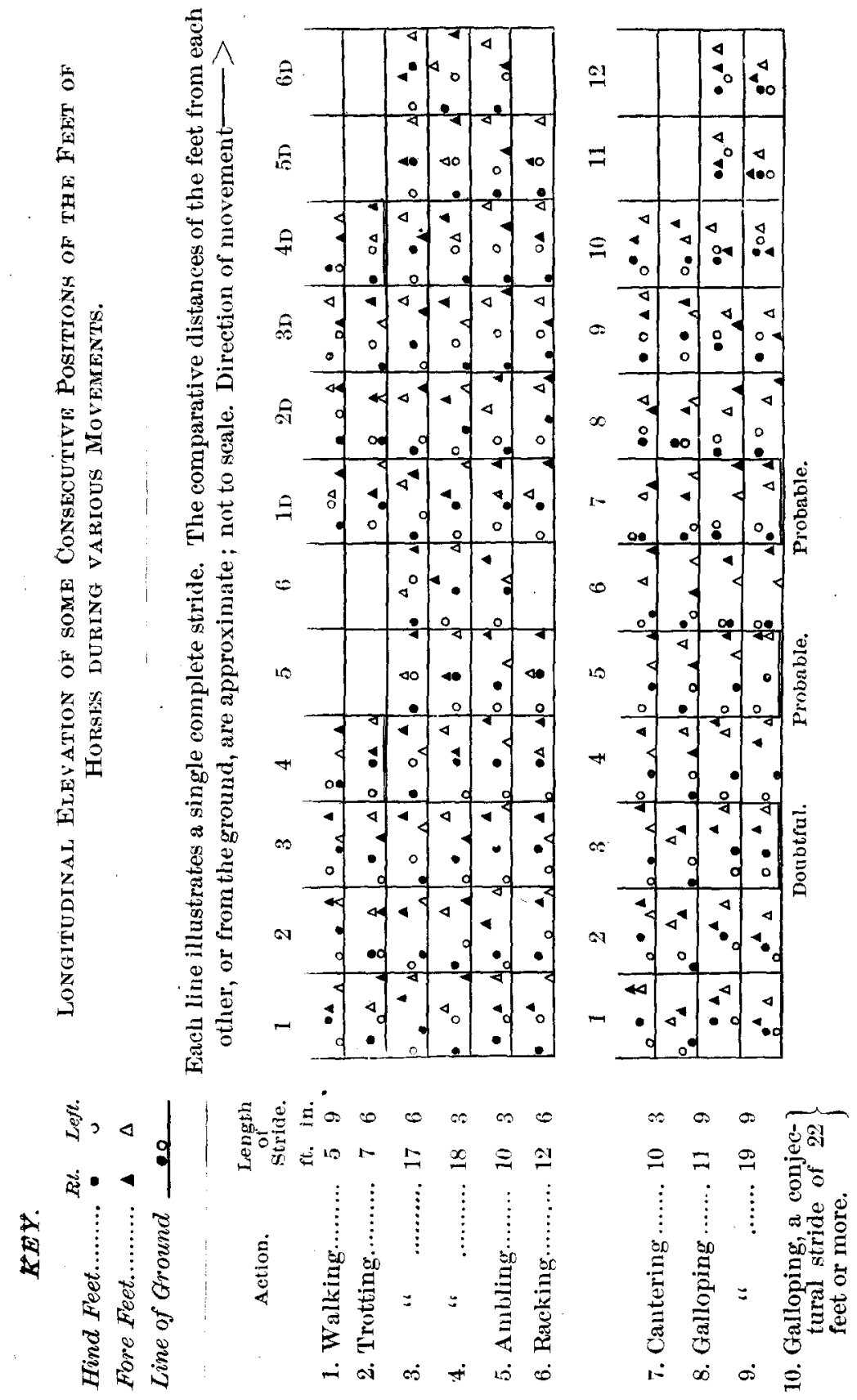
strike at about 38 or 40 inches to the rear of the fore foot. When both feet have reached the ground, the right hind leg is stretched back almost to its fullest extent, with the pastern nearly horizontal, while the left fore leg is flexed under the body. As the legs approach a vertical position the pasterns are gradually lowered, and act as springs to break the force of the concussion until they are bent nearly at right. angles with the legs.

At this period the left fore foot is raised to its greatest height, and will frequently strike the elbow, while the right hind foot is but little raised from the ground and is about to pass to the front of the left hind.

The pasterns gradually rise as the legs decline backwards until the right fore foot has left the ground and the last propelling force is being exercised by the left hind foot; which accomplished, the animal is in mid air.

The right hind foot continues its onward motion until it is sometimes much in advance of its lateral fore foot, the former, however, being gradually lowered, while the latter is being raised. The right hind and both fore legs are now much flexed, while the left hind is stretched backward to its greatest extent with the bottom of the foot turned upwards, the left fore leg is being thrust forwards and gradually straightened, with the toe raised as the foot approaches the ground; which accomplished, with a substitution of the left limbs for the right we find them in the same relative positions as when we commenced our examination, and one-half of the stride is completed.

With slight and immaterial differences, such as might be caused by irregularities of the ground, these movements are repeated by the other pair of diagonals, and the entire stride is then complete.

Line 4 illustrates a stride of 18 feet 3 inches, and the order of supporting feet are :-

1. The right fore foot.

2. The left hind and right fore feet.

3. The left hind foot.

4. Without support.

5. The left tore foot.

6. The right hind and left fore feet.

7. The right hind foot.

8. Without support.

It appears somewhat remarkable that until the results of M. Marey's 
experiments and of those obtained by electro-photography were published, many experienced horsemen were of opinion that during the action of trotting at least one foot of a horse was always in contact with the ground.

If the entire stride of a trotting horse is divided into two portions, representing the comparative distances traversed by the aggregate of the body while the feet are in contact with, and while they are entirely clear of, the ground; the relative measurements will be found to vary very greatly, they being contingent upon length of limb, weight, speed, and other circumstances.

Heavily built horses will sometimes merely drag the feet just above the surface, but, in every instance of a trot, the weight of the body is really unsupported twice during each stride (see stride 2, positions 4 and 4D). It sometimes happens that a fast trotter, during the two actions of a stride, will have all his feet clear of the ground for a distance exceeding one-half of the length of the entire stride; this elasticity of movement is however exceptional.

The action of a fast-trotting horse while drawing a vehicle is very different from his action under the saddle; in the latter case, the hind legs are kept thrust back for a longer period, and their final forward movement is much more rapid.

THE AMBLE.

Assuming our observation of this movement to commence when, during a stride of about 10 feet, the left hind foot has just struck the ground slightly to the rear of where the right fore foot is resting; the left fore leg will be well advanced but still flexed, with the toe pointed downwards, and the right hind foot having been the last to leave the ground, will be thrust backwards with the pastern nearly horizontal.

As the right fore foot leaves the ground, the left fore leg is gradually straightened during its thrust forwards; the right hind foot in the meantime is gradually advancing, and the horse is supported on the left hind foot alone.

The left fore foot is now brought to the ground, and the body rests on the left laterals, with the right laterals suspended between them.

As the left fore leg attains a vertical position, its lateral leaves the ground, and the support of the body devolves on the left fore foot alone, the right fore leg being considerably flexed, with the foot in advance of the left fore leg. 
The right hind foot now strikes the ground, and one-half of the stride is accomplished; these movements are repeated with a change of the limbs for the remaining portion of the stride, and the horse is again in the position in which we first observed him.

We shall see by reference to stride No. 5 the consecutive supporting feet to be :

1. The left hind foot.

2. The left hind and left fore feet-laterals.

3. The left fore foot.

4. The left fore and right hind feet-diagonals.

5. The right hind foot.

6. The right hind and right fore feet-laterals.

7. The right fore foot.

8. The right fore and left hind feet-diagonals.

The right fore foot being raised, the horse is again in the first position.

The amble and the walk are the only regular progressive movements of the horse wherein the body is never without the support of one or more legs, in all others the weight is entirely off the ground for a longer or shorter period.

THE RACK OR PACE.

The rack differs from the trot in the nearly synchronous action of the laterals instead of the diagonals.

In some countries the rack is naturally adopted by the horse as one of his gaits, but it is probably caused by the effects of training exercised over many generations of his ancestors.

The movements already described are regular in their action, and a stride may be divided into two parts, which are essentially similar to each other.

THE CANTER

and the gallop, however, cannot be so divided, and a complete stride in either of those gaits is a combination of several different movements.

The canter is usually regarded as a slow gallop, probably from the facility with which a change from one gait to the other can be effected; an important difference will, however, be observed.

Assuming a horse after his propulsion through the air, during a stride of 10 feet, to have just landed on his left hind foot, the right hind foot will be on the point of passing to the front of the left. The left fore leg will be thrust forward and nearly straight, while the right 
fore leg will be flexed with the foot elevated about 12 inches from the ground, and somewhat behind the vertical of the breast. The left fore foot being brought to the ground, the body is supported by the laterals; the right hind foot is, however, quickly lowered, and performs its share of support. The left hind foot is then raised, and the right hind and left fore legs assume the weight, the former being nearly vertical, and the latter inclined well back, the right fore foot is thrust well forward, and is just about to strike the ground; when it does, three feet again share the support, they being the two fore and the right hind. The left fore font now leaves the, ground, and we again find the support furnished by the laterals, the right instead of', as before, the left.

The right hind foot is raised when the right fore leg becomes vertical ; this latter, which now sustains the entire weight, gives the final effurt of propulsion, and the body is hurled into the air.

The descent of the left hind foot completes the stride, and the consecutive movements are repeated.

In stride No. 7 we learn that during the canter the support of the body is derived from--

1. The left hind foot.

2. The left hind and left fore feet-laterals.

3. Both hind and the left fore feet.

4. The right hind and left fore feet-diagonals.

5. The right hind and both fore feet.

6. The right hind and right fore feet-laterals.

7. The right fore foot alone, on which he leaves the ground.

THE GAILOP OR RUN.

This movement has in all ages been employed by artists to convey the impression of rapid motion, although, curiously enough, the attitude in which the horse has been almost invariably depicted is one which is impracticable during uniform progressive motion.

When during a rapid gallop, with a stride of 20 feet, a horse after his flight through the air lands on his left hind foot, the right hind will be suspended over it at an elevation of 12 or 15 inches, and several inches to the rear of and above it the sole of the right fore foot will be turned up almost horizontally, the left fore leg is flexed with the foot under the breast at a height of 18 or 20 inches.

The right hind foot strikes the ground some 36 inches in advance of the left hind, each as they land being forward of the centre of gravity. 
The body is now thrust forward, and while the right hind pastern is still almost horizontal, the left hind foot leaves the ground. At this time the left fore leg is perfectly straight, the foot, with the toe much higher than the heel, is thrust forward to a point almost vertical with the nose, and at an elevation of about 12 inches the right fore knee is bent at right angles, and the foot suspended under the breast at several inches greater elevation than the left fore foot.

The left fore foot now strikes the ground, 96 inches in advance of the spot which the right hind foot is on the point of leaving, and for a brief space of time the diagonals are upon the ground together. The left fore leg, however, immediately assumes the entire responsibility of the weight, and soon attains a vertical position, with its pastern at right angles to it.

In this position the right hind foot is thrust back to its fullest extent, at an elevation of 12 or 14 inches, with the pastern nearly horizontal. The left hind foot is considerably higher and somewhat more forward ; the right fore leg is straight, stretched forward, with the foot about 15 inches from the ground, and almost on a perpendicular line from the nose. The right fore foot strikes the ground 48 inches in advance of the left fore, which, having nearly performed its office, is preparing to leave the ground; the animal will then be supported on the right fore foot alone, which immediately falls well to the rear of the centre of gravity, which is sometimes passed by the left hind foot at a height of about 12 inches; the right hind foot is some distance in the rear, and the left fore foot, at a height of 24 inches, is suspended somewhat in advance of its lateral.

In this position the horse uses the right fore foot for a final act of propulsion, and is carried in mid air for a distance of 60 inches, after which the left hind foot descends, the stride is completed, and the consecutive motions renewed.

The measurements and positions herein given do not pretend to exactness, as they must depend to some extent upon the capability, training, and convenience of the animal; but they may be accepted as representing an average stride of 20 feet with a horse in fair condition for racing.

From this analysis it will be seen, by reference to stride 9 , that a horse, during an ordinary gallop, is supported consecutively by:

1. The left hind foot,

2. Both hind feet, 
3. The right hind foot,

4. The right hind and left fore feet,

5. The left fore foot,

6. Both fore feet,

7. The right fore foot, with which he leaves the ground, while the only position in which we find him entirely without support is when all the legs are flexed under his body.

It is highly probable, however, that more exhaustive experiments with long-striding horses in perfect training, will discover there is sometimes an interval of suspension between the lifting of one fore foot and the descent of the other; and also between the lifting of the second hind foot which touches the ground, and the descent of its diagonal fore foot (see imaginary stride 10). Should this latter be the case, it will, from the necessary positions of the other limbs, afford but a very shadowy pretext for the conventional attitude used by artists to represent a gallop. It is extremely doubtful if there can be any interval of suspension between the lifting of one hind foot and the descent of the other, no matter what the length of stride.

Many able scientists have written on the theory of the gallop, but I believe Marey was the first to demonstrate, that in executing this movement, the horse left the ground with a fore foot and landed on a hind foot.

\section{THE LEAP.}

There is little essential difference in general characteristics of either of the several movements that have been described, but with a number of experiments made with horses while leaping, no two were found to agree in the manner of execution. The leap of the same horse at the same rate of speed, with the same rider, over the same hurdle, disclosed much variation in the rise, clearance, and descent of the animal. Apart from this, the horses were not thoroughly trained leapers, and the results are perhaps not representative of those that would be obtained from the action of a well-trained hunting horse. A few motions were, however, invariable. While the horse was raising his body to clear the hurdle, one hind foot was always in advance of the other, and exercised its last energy alone.

On the decent, the concussion was alwavs received by one fore foot, supported by the other more or less rapidly, and sometimes as much as 30 inches in advance of where the first one struck, followed by the Whole No. Vol. CXV.-(Third Series, Vol. lxxxv.) 
hind feet also, with intervals of time and distance between their several falls. It is highly probable future experiments will prove these observations to be invariable in leaping.

It is highly probable that these photographic investigations, which were executed with wet collodion plates with exposures not exceeding in some instances the one five-thousandth part of a second, will dispel many popular illusions as to gait, and that future and more exhaustive experiments, with all the advantages of recent chemical discoveries, will completely unveil to the artist all the visible muscular action of men and animals during their most rapid movements.

The employment of automatic apparatus for the. purpose of obtaining a regulated succession of photographic exposures is too recent for its value to be properly understood, or to be generally used for scientific experiment; at a future time, the pathologist, the anatomist, and other explorers for hidden truths will find it indispensable for their complex investigations.

\section{CHARCOAL AS APPLIED TO THE DEPOSITION OF GOLD FROM CHLORINE SOLUTIONS, AND ITS PER- FECT SEPARATION FROM COPPER AND OTHER IMPURITIES.}

\section{By William Morris Davis.}

[A paper read at the Stated Meeting of the Franklin Institute, March 21, 1883.]

As preliminary to the subject, and necessary to a just appreciation of its value in utilizing the refractory ores of gold, it may be remarked that in our country there exist immense amounts of auriferous sulphides, and arsenides, which have not been deemed available on account of their refractory nature, or their low value in gold.

Smelting has only been applied to such ores when they carried a comparatively high value in gold. Kerl teaches that "ores containing combined gold to the amount of $\$ 20$ per ton cannot be profitably fused with lead, even could they be raised without mining cost."

By chlorination, ores containing combined gold to the amount of $\$ 10$ per ton can be profitably worked, mining cost included.

This process has not found general application for reasons which will be considered hereafter. 